BMJ Open Sport \& Exercise Medicine

\title{
Physical activity and the insurance industry
}

Diarmuid Coughlan

International research has consistently shown that adults who take regular leisuretime physical activity (LTPA) have better health outcomes, lower rates of chronic non-communicable diseases (NCDs) and premature deaths. ${ }^{1}$ Increasing physical activity is a cornerstone of many governments' public health policy. However, even among today's adolescents, rates of insufficient physical activity are stubbornly high, approximately $81.0 \% \quad(95 \%$ uncertainty interval 77.8-87.7) worldwide. $^{2}$ The 2020 WHO guidelines on physical activity and sedentary behaviour provide evidencebased recommendations for policy-makers within and outside the health sector, including transport, education, workplaces, sport, parks and recreation. ${ }^{3}$ However, little is made of the impact that the insurance industry may have in helping the public be physically active into the future.

Insurance markets exist for all sorts of goods and services. An array of public and private insurance programmes exists in countries around the world. For those living in the UK, Vitality, the private life and health insurer, is one of the most visible insurance companies that offers insurees the opportunity to link data from wearable physical activity trackers to their policy. They offer incentives such as a reduced price for a 'smart' watch, sporting gear and gym membership. As private insurance companies are profit maximisers, they will want to 'cream skim' the wealthy fit well into their insurance pool as they will pay the monthly premiums but have lower chances of incurring costs. Information is crucial. Physical activity trackers reduce the asymmetry of information between insurer and insuree. This lowers the moral hazard risk to the insurer (ie, that the insuree will take risks without having to suffer consequences). I imagine that actuaries at insurance companies figured out the extent to which active insurees are more profitable. With the availability of longitudinal data, this can now be estimated with public data.
Colleagues from the National Cancer Institute and the Centers for Disease Control \& Prevention and I have published two studies using trajectory modelling based on the NIH-AARP Diet and Health Study showing the association between long-term benefits of physical activity on premature mortality and healthcare costs. The paper by SaintMaurice et al, based on 315059 Americans, showed that long-term participation in physical activity might lower all-cause mortality risk by $29 \%-36 \%$ compared with a consistently inactive reference group. ${ }^{4}$ Interestingly, participants who became physically active later in adulthood ( $>40$ years) may also have a comparable lower risk of mortality in the range of $32 \%-35 \%$ over the observation period.

The second paper published in March 2021 in this journal is based on a subset that agreed to Medicare data linkage. ${ }^{5}$ This is the federal health insurance programme for those over 65 years of age in the USA. To mitigate selection bias, we restricted the analytic sample to the 21750 participants in the study that were 65 years of age when they first entered the Medicare programme. We found that individuals who maintained or increased physical activity from adolescence throughout adulthood were associated with lower healthcare costs in later life during the observation period (see figure 1).

Again, individuals who maintained longterm participation in physical activity were associated with 14\%-16\% lower healthcare costs per annum than the consistently inactive reference group. Interestingly, individuals who increased their physical activity later in adulthood also had lower healthcare costs in the range of $10 \%-22 \%$ per annum.

Both studies are based on self-report LTPA at four different time intervals. Physical activity trackers will provide objectively measured data, for insurers to work with in terms of estimating the likely association between physical activity and their outcome of interest. The question is whether private insurers will exploit the data from physical activity trackers 


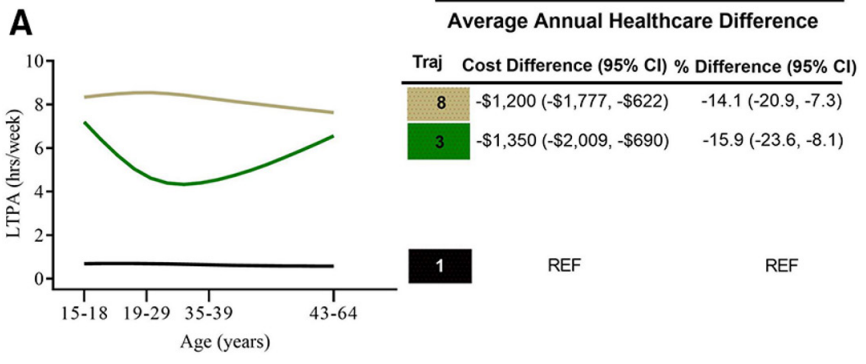

B

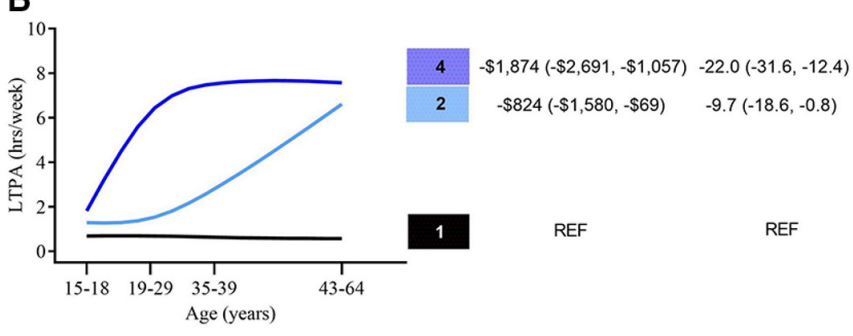

C

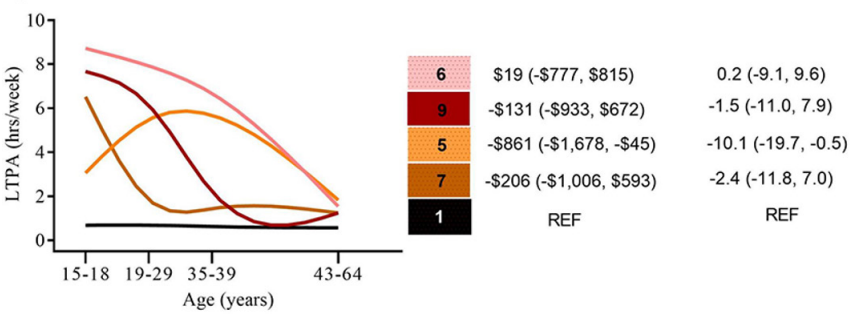

Figure 1 Association between leisure-time physical activity (LTPA) trajectory and average annual healthcare costs in later life. (A) Maintainers. (B) Increasers. (C) Decreasers. Reference: Traj 1 US\$8453/year. ${ }^{5}$

of their insurees to 'class' individuals even further? In the case of Vitality life insurance policies, they offer a programme, called 'Optimiser', to the participants' plan, which has the incentive of reduced premiums based on access to tracker data. An affiliate company, John Hancock, introduced a similar programme in the USA and AIA in Australia. ${ }^{6}$ This is an opportunity for insurees to lower premiums by providing verified evidence of their health status. Digital health technologies are really helpful to insurance companies as verification. Once enrolled, the question then becomes of sustaining physical active behaviours over the long term.

Encouraging and sustaining behavioural change is challenging. A position paper by Altmann-Richer outlined that the long-term positive behaviour change is likely to be based on intrinsic motivation (innate psychological needs-autonomy, competence and relatedness) than extrinsic motivation (monetary rewards in the form of discounted premiums). ${ }^{7}$ Examples of insurance companies appealing to intrinsic motivation are rare. Voluntary Health Insurance in Ireland and Discovery in South Africa, among others, have a commercial sponsorship arrangement with parkrun, the successful global community run that is a weekly, timed, $5 \mathrm{~km}$ event, which could be argued appeals to intrinsic motivation traits. An issue that private health insurance companies are likely to have is if insurees can switch providers easily. In this case, funding behavioural change initiatives is not financially appealing as another insurer would reap the rewards. Only in closed systems, such as Kaiser Permanente in the USA, would this become an attractive proposition.

In recent years, the development of mass-market wearable physical activity technology has evolved dramatically. According to the 2018 Government \& Academic Omnibus Survey assessing wearable use, an estimated 1 in 5 US adults do and most $(\sim 80 \%)$ adults are willing to share their data with at least one other person/organisation. ${ }^{8}$ This willingness ranged from $47.7 \%$ with a health insurer to $76.3 \%$ with their healthcare provider. ${ }^{8}$ As the insurance industry is moving towards embracing the "convergence of behavioural economics and consumer technology', ${ }^{9}$ regulatory concerns from data privacy to market segmentation will inevitably arise.

In this editorial, I am making the point that the insurance industry, both public and private, ought not to be overlooked in addressing physical inactivity. The recognised relationship between physical activity and NCDs means that claims on health, life, income protection and critical illness insurance policies are likely to be higher for those insurees who are less physically active. ${ }^{7}$ Essentially, the insurance industry has 'skin in the game' and probably the data to prove it.

\section{Twitter Diarmuid Coughlan @D6Coughlan}

Acknowledgements The author would like to thank Professor Luke Vale (Newcastle University) and Professor Evert Verhagen (Amsterdam UMC) for reviewing earlier drafts.

Funding The authors have not declared a specific grant for this research from any funding agency in the public, commercial or not-for-profit sectors.

Competing interests None declared.

Patient consent for publication Not required.

Provenance and peer review Commissioned; externally peer reviewed.

Open access This is an open access article distributed in accordance with the Creative Commons Attribution Non Commercial (CC BY-NC 4.0) license, which permits others to distribute, remix, adapt, build upon this work non-commercially, and license their derivative works on different terms, provided the original work is properly cited, appropriate credit is given, any changes made indicated, and the use is non-commercial. See: http://creativecommons.org/licenses/by-nc/4.0/.

\section{ORCID iD}

Diarmuid Coughlan http://orcid.org/0000-0002-5348-3750

\section{REFERENCES}

1 Lee I-M, Shiroma EJ, Lobelo F. Impact of Physical Inactivity on the World's Major Non-Communicable Diseases. Lancet 2012;380:219-29.

2 Guthold R, Stevens GA, Riley LM, et al. Global trends in insufficient physical activity among adolescents: a pooled analysis of 298 population-based surveys with 1.6 million participants. Lancet Child Adolesc Health 2020;4:23-35.

3 WHO. Who guidelines on physical activity and sedentary behaviour. Geneva: World health organisation, 2020.

4 Saint-Maurice PF, Coughlan D, Kelly SP, et al. Association of leisuretime physical activity across the adult life course with all-cause and cause-specific mortality. JAMA Netw Open 2019;2:e190355. 
5 Coughlan D, Saint-Maurice PF, Carlson SA, et al. Leisure time physical activity throughout adulthood is associated with lower Medicare costs: evidence from the linked NIH-AARP diet and health study cohort. BMJ Open Sport Exerc Med 2021;7:e001038.

6 Spender A, Bullen C, Altmann-Richer L. Wearables and the Internet of things: considerations for the life and health insurance industry. $\mathrm{Br}$ Actuar J 2019;24:e22:1-31.

7 Altmann-Richer L. Physical activity tracking in private insurance: a prospective framework for the policy implications of the use of physical activity trackers by private insurers. London: Institute and Faculty of Actuaries, 2017.

8 Hyde ET, Omura JD, Fulton JE, et al. Physical activity surveillance using wearable activity monitors: are us adults willing to share their data? Am J Health Promot 2020;34:672-6.

9 PRNewswire. John Hancock leaves traditional life insurance mode behind to Incentivize longer, healthier lives. Bostion, USA, 2018.

Available: https://www.prnewswire.com/news-releases/john-hancockleaves-traditional-life-insurance-model-behind-to-incentivize-longerhealthier-lives-300715351.htm 